\title{
Thin liquid water clouds: their importance and our challenge
}

Article

Published Version

Turner, D., Vogelmann, A., Austin, R., Barnard, J., CadyPereira, K., Chiu, J. C., Clough, S., Flynn, C., Khaiyer, M., Liljegren, J., Johnson, K., Lin, B., Long, C., Marshak, A., Matrosov, S., McFarlane, S., Miller, M., Min, Q., Minnis, P., O'Hirok, W., Wang, Z. and Wiscombe, W. (2007) Thin liquid water clouds: their importance and our challenge. Bulletin of the American Meteorological Society, 88 (2). pp. 177-190. ISSN 1520-0477 doi: https://doi.org/10.1175/BAMS-88-2-177 Available at https://centaur.reading.ac.uk/16768/

It is advisable to refer to the publisher's version if you intend to cite from the work. See Guidance on citing.

To link to this article DOI: http://dx.doi.org/10.1175/BAMS-88-2-177

Publisher: American Meteorological Society

All outputs in CentAUR are protected by Intellectual Property Rights law, including copyright law. Copyright and IPR is retained by the creators or other copyright holders. Terms and conditions for use of this material are defined in the End User Agreement. 


\section{CentAUR}

Central Archive at the University of Reading

Reading's research outputs online 


\title{
THIN LIQUID WATER CLOUDS Their Importance and Our Challenge
}

\author{
by D. D. Turner, A. M. Vogelmann, R. T. Austin, J. C. Barnard, K. Cady-Pereira, \\ J. C. Chiu, S. A. Clough, C. Flynn, M. M. Khaiyer, J. Liljegren, K. Johnson, \\ B. Lin, C. Long, A. Marshak, S. Y. Matrosov, S. A. McFarlane, M. Miller, \\ Q. Min, P. Minnis, W. O'Hirok, Z. Wang, AND W. Wiscombe
}

\begin{abstract}
Many clouds important to the Earth's energy balance contain small amounts of liquid water, yet despite many improvements, large differences in retrievals of their liquid water amount and particle size still must be resolved.
\end{abstract}

\begin{abstract}
C louds play a critical role in modulating the radiative transfer in the atmosphere, and the way in which clouds interact with the atmosphere and impact the Earth's radiative energy balance is one of the primary uncertainties in global circulation model (GCM) simulations of $\mathrm{CO}_{2}$ doubling (Houghton et al. 2001; Stephens et al. 2002). The specification of the macrophysical, microphysical, and optical properties of clouds is among the largest uncertainties in estimating the impact of clouds on the radiative fields in GCMs. Low-level liquid water clouds are arguably the
\end{abstract}

AFFILIATIONS: TURNER-University of Wisconsin-Madison, Madison, Wisconsin; Vogelmann, Johnson, AND Miller-Brookhaven National Laboratory, Upton, New York; AustiN-Colorado State University, Fort Collins, Colorado; BARNARD, FLYNN, Long, AND MCFARLANE-Pacific Northwest National Laboratory, Richland, Washington; Cady-Pereira and Clough-Atmospheric and Environmental Research, Inc., Lexington, Massachusetts; CHIUUniversity of Maryland, Baltimore County, Baltimore, Maryland; KHAIYER-AS\&M, Hampton, Virginia; LILJEGREN-Argonne National Laboratory, Argonne, Illinois; LIN AND MINNIs-NASA Langley Research Center, Hampton, Virginia; MARSHAK-NASA Goddard Space Flight Center, Greenbelt, Maryland; MATrosov-CIRES, University of Colorado, and NOAA/Earth System Research Laboratory, Boulder, Colorado; MIN-State University of New York at Albany, Albany, New York; O'HıROK-University of California, simplest type of cloud to observe and are generally regarded as being a solved problem. However, the results reported here indicate that huge discrepancies exist among different observation techniques for even a simple case.

This paper is one in a series that highlights the achievements that have occurred in remotely observing cloud properties, and addresses the current issues that remain. For reasons that will be discussed, we limit the focus of this paper to clouds that contain small amounts of liquid water. While these clouds
Santa Barbara, Santa Barbara, California; WANG—University of Wyoming, Laramie, Wyoming; WiscomBE-Brookhaven National Laboratory, Upton, New York, and NASA Goddard Space Flight Center, Greenbelt, Maryland CORRESPONDING AUTHOR: Dr. David D. Turner, University of Wisconsin-Madison, 1225 West Dayton Street, Madison, WI 53706

E-mail: dturner@ssec.wisc.edu

The abstract for this article can be found in this issue, following the table of contents.

DOI:I0.II75/BAMS-88-2-177

In final form I August 2006

@2007 American Meteorological Society 
are common and are among the simplest to treat, they are misleadingly difficult to observe accurately. Our objective is to discuss a recent cloud property retrieval intercomparison exercise and illustrate why these results are potentially important for climate through the radiative flux. The results from the intercomparison suggest that we are further than we may have expected from accurately observing these cloud properties, and that a concerted effort is needed to rectify these discrepancies.

\section{THE IMPORTANCE OF “THIN" WATER} CLOUDS. The description of clouds needed for climate studies requires both their microphysical properties, such as their liquid water content and drop size distribution, and properties that are used to describe their interaction with radiation, such as their optical depth and effective radius. (See the "Cloud microphysics and remote sensing" sidebar for a brief summary of commonly used microphysical and radiative properties and their interrelationships.) We focus our attention here on thin liquid water clouds that have a liquid water path (LWP) less than $100 \mathrm{~g} \mathrm{~m}^{-2}$ (we will refer to these clouds as "thin" liquid water clouds). These clouds are common and are relatively simple to address compared to upper-tropospheric cirrus clouds, for example. This is because liquid water clouds tend to reside lower in the atmosphere, which makes them easier to study by surface remote sensing. They are also composed of spherical water drops whose scattering properties are described well by Mie theory (Mie 1908), unlike ice clouds that may contain multiple crystal shapes and require much more complicated scattering treatments.

Although these clouds might not be as eye catching as those that are central to extreme weather events, their extensive coverage means that they cannot be ignored. Analyses from the International Satellite Cloud Climatology Project (ISCCP) reveal that the global mean cloud fractional coverage is $68.6 \%$ (Rossow and Schiffer 1999), but deep convective clouds cover only $2.6 \%$ of the globe. However, the ISCCP study found that low- and midlevel clouds, which often contain liquid water, have mean water paths of only 51 and $60 \mathrm{~g} \mathrm{~m}^{-2}$, respectively, and cover $27.5 \%$ and $19 \%$ of the globe. This general result from ISCCP is supported by surface observations from the Climate Research Facilities (CRFs) operated by the U.S. Department of Energy's Atmospheric Radiation Measurement (ARM) program (Ackerman and Stokes 2003), which are strategically located in different climate regimes. The distribution of LWP at a continental midlatitude site reveals that over $50 \%$ of the liquid water clouds have LWPs below $100 \mathrm{~g} \mathrm{~m}^{-2}$ (Marchand et al. 2003). Also, approximately $80 \%$ of the liquid-bearing clouds in the Arctic have LWPs below this threshold (Shupe and Intrieri 2004), as do nearly $90 \%$ of the nonprecipitating liquid clouds over the tropical island of Nauru during convectively suppressed conditions (McFarlane and Evans 2004), although this may not be representative of cumulus updraft regions. The many types of clouds that may fall into this broad classification include stratus decks, cumulus fields, and mixed-phase clouds.

With such high frequencies of occurrence across the globe, these thin liquid water clouds are undeniably important to many different aspects of atmospheric science and are intertwined with the broader climate. Their global frequency certainly impacts the global radiative energy balance and includes the surface longwave emission in the Arctic (Shupe and Intrieri 2004) and the shortwave albedo impact of the extensive marine stratus decks (Hartmann et al. 1992), of which many are within our definition of thin (cf. Zuidema and Hartmann 1995). In fact, the albedo of these subtropical marine boundary layer clouds are a particularly important concern because climate models simulate them poorly (Zhang et al. 2005; Bender et al. 2006); yet, their simulation and response to changing environmental conditions is the main source of uncertainty in tropical cloud feedbacks simulated by climate models (Bony and Dufresne 2005).

Clouds with a low liquid water path are also intricately linked with atmospheric aerosol. The Intergovernmental Panel on Climate Change (Houghton et al.2001) indicated that the climate forcing with the greatest range of uncertainty was that for the first aerosol indirect effect. The first indirect effect leads to an increase in the reflection of solar radiation by the cloud, whereby an increase in aerosols causes an increase in droplet concentration and a decrease in droplet size for fixed liquid water content (Twomey 1974). Improving our understanding of this effect in climate model simulations requires accurate observations of both the cloud LWP and $r_{e}$ in association with the aerosol fields. This understanding is particularly important for the study of possible aerosol effects on cloud lifetime, where thin clouds bookend the beginning and end of the cloud life cycle.

THE CHALLENGE. Because these clouds are thin, potentially mixed phase, and often broken (i.e., have large 3D variability), it is challenging to accurately retrieve their microphysical properties. An intriguing feature of these thin clouds is that the radiative fluxes are very sensitive to small changes in the LWP when 


\section{CLOUD MICROPHYSICS AND REMOTE SENSING}

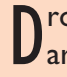
op size distribution and LWC are the two most basic properties commonly used to describe the microphysical state of a liquid water cloud. The drop size distribution is the number density of water drops $n$ as a function of drop radius $r$. An integration over the mass of the drop size distribution yields the liquid water content, that is,

$$
\mathrm{LWC}=\frac{4 \pi}{3} \rho_{l} \int r^{3} n(r) d r
$$

where $\rho_{l}$ is the density of liquid water. Another bulk term used is LWP, which is the vertical integral of the LWC through the depth of the cloud. The drop size distribution and liquid water content can be measured in situ by airborne instrumentation. While this type of information is vital to cloud studies, aircraft flights are expensive, are not practical to use in situ sampling to obtain the type of long-term observations needed for cloud and climate studies, and inherently suffer from questions about representativeness.

Remote sensing from the surface or satellite instrumentation can provide the needed long-term record by a variety of techniques that determine cloud properties from the radiative energy that is emitted, transmitted, or reflected by the cloud. Many remote sensing techniques cannot necessarily obtain the cloud microphysical properties directly; rather they are able to determine their radiative equivalents that are then used to infer or retrieve the cloud microphysical properties of interest. The most fundamental property that defines how a cloud interacts with shortwave and longwave radiation is its optical depth $\tau$, which is an indication of the cloud opacity for a given wavelength of radiation. It is the physical depth of the cloud measured in units of total mean-free path ${ }^{\mathrm{SBI}}$ (Bohren and Clothiaux 2006). For a rule of thumb, an optical depth of 10 is where one can no longer see the sun's disk through a cloud (Bohren et al. 1995). At solar and near-infrared wavelengths, where the cloud drop radii are generally much greater than the wavelength of the incident radiation, cloud optical depth $\tau$, is related to LWP by (Stephens 1994)

$$
\tau \approx \frac{3 \mathrm{LWP}}{2 \rho_{l_{e}}},
$$

where $r_{e}$ is the effective radius. The effective radius, which is the areaweighted mean radius of the cloud drops, is defined as

$$
r_{e}=\frac{\int_{0}^{\infty} r^{3} n(r) d r}{\int_{0}^{\infty} r^{2} n(r) d r},
$$

where $r$ is the drop radius and $n(r)$ is the drop size distribution that gives the number of particles per unit volume within the radius $r$ and $r+d r$. Note that the effective radius is proportional to the ratio of the volume of the cloud droplets to their projected area. Because the cloud optical depth and effective radius are obtained from remotely sensed radiative fields, they have the added advantage of being able to directly describe how clouds interact with the Earth's radiative energy balance, a key interest in climate studies.

SBI The mean-free path is the average distance a photon travels between interactions with cloud drops the LWP is small (e.g., Sengupta et al. 2003), which requires a particularly high degree of accuracy in observations and modeling. As described later, this sensitivity also presents a challenge for their accurate remote sensing. (For a further explanation, see the "Cloud radiative sensitivity" sidebar. $)^{1}$

The primary instrument for observating the cloud LWP from the surface is the microwave radiometer (MWR). ${ }^{2}$ Retrievals from the MWR are widely used because, in general, they can retrieve LWP for the wide range of values found in the atmosphere without saturating, the LWP are retrieved without requiring additional information on the cloud drop size (as do many other approaches), and they can operate 24 hours a day at a temporal resolution needed for cloud studies (e.g., every 5 s). However, recent research has found that uncertainties exist in the LWP retrievals that limit the attainable accuracy to between 20 and $30 \mathrm{~g} \mathrm{~m}^{-2}$ (Liljegren and Lesht 1996; Westwater et al. 2001; Marchand et al. 2003; Crewell and Löhnert

${ }^{1}$ This discussion applies to the small cloud area within the instrument's field of view for which the cloud properties (optical depth, LWP, effective radius) are considered to be constant for the purposes of the retrievals. However, it is important to recognize that these properties can vary across a cloud, and that this area-to-area horizontal variability must be observed and modeled to get the radiative transfer correct. Even stratus clouds, which are arguably one of the most horizontally homogeneous types of clouds that occur, can exhibit considerable horizontal structure (e.g., Slingo et al. 1982; Davis et al. 1999).

${ }^{2}$ The most common type of MWR measures the emission of the microwave radiation from the atmosphere at two frequencies: one on the 22.2-GHz water vapor absorption line (e.g., at $23.8 \mathrm{GHz}$ ) and one in a window region (e.g., at 31.4 GHz). Using information about the atmospheric temperature profile, including estimates of the cloud temperature, the radiance measured at these two frequencies is inverted to retrieve the cloud LWP, as well as the amount of precipitable water vapor in the column (e.g., Liljegren et al. 2001). 


\section{CLOUD RADIATIVE SENSITIVITY}

ongwave and shortwave radiative

L fluxes are very sensitive to small changes in the cloud LWP when the LWP is small, that is, $<100 \mathrm{gm}^{-2}$, and thus the radiative properties of these clouds must be well understood to capture them correctly in climate models. This point is illustrated in Fig. $\mathrm{SBI}$, which shows radiative transfer model calculations for broadband longwave and shortwave fluxes at the SFC and TOA as a function of cloud LWP. Solar fluxes are diurnal averages for an equinox day over a continental site at $37^{\circ} \mathrm{N}$. In this example, the cloud is modeled as a uniform overcast cloud (i.e., a plane-parallel, or ID, cloud).

This figure is only intended to illustrate the sensitivity of the radiative flux to cloud properties, and on a location-bylocation basis, the sensitivity will vary slightly depending on additional factors, including the sun angle, surface albedo, cloud height, and profile of temperature and water vapor content.
Here, the sensitivity to the atmospheric profile of temperature and water vapor content are illustrated using the standard midlatitude summer and midlatitude winter profiles (McClatchey et al. 1972). The warmer midlatitude summer profile results in a greater emission of longwave fluxes at the surface and TOA, and its larger water vapor content absorbs more solar radiation and reduces the transmission of shortwave fluxes. Two effective radii are used, which are generally representative sizes for continental $(6 \mu \mathrm{m})$ and maritime $(12 \mu \mathrm{m})$ clouds. Fluxes are more sensitive to LWP changes for the smaller effective radii because they correspond to larger changes in optical depth. This follows from Eq. (SBI), which indicates that optical depth is inversely proportional to effective radius, and is indicated by the dual optical depth $x$ axes that correspond to the same LWP axis. The longwave and shortwave sensitivities (bottom row) indicate a similar range of sensitivities for the lowest LWP, but the longwave fluxes become insensitive to changes in LWP when the LWP is larger than $40 \mathrm{~g} \mathrm{~m}^{-2}$ while the shortwave fluxes continue to show some sensitivity even through $100 \mathrm{~g} \mathrm{~m}^{-2}$. The sensitivities at specific wavelengths may differ, especially from those given here for the broadband fluxes, which is a feature exploited in remote sensing of cloud properties.

This example assumed that the sky is $100 \%$ overcast and homogeneous (i.e., no horizontal variability in the cloud field), and that the cloud does not change during the day. However, if the cloud field was broken and the cloud amount and cloud fraction were treated in these calculations, additional nonlinearities would be exhibited (e.g., Schmetz 1984).
FIG. SBI. Model calculations show the sensitivity of broadband longwave and shortwave fluxes at the surface (SFC) and TOA to cloud LWP and effective radius $\left(r_{\mathrm{e}}\right)$. Optical depths corresponding to the LWP scale are given at the bottom for cloud drop effective radii of 6 (solid line) and 12 $\mu \mathrm{m}$ (dashed line). The cloud is located between 900 and 1300 $\mathrm{m}$ in standard midlatitude summer (red) and midlatitude winter (blue) atmospheres. Solar fluxes are diurnal averages for an equinox day at a continental site at $37^{\circ} \mathrm{N}$. The top two rows show the absolute fluxes, and the bottom row shows the flux sensitivity, in terms of the lo-

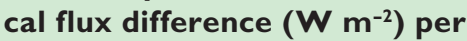
LWP difference $\left(\mathrm{g} \mathrm{m}^{-2}\right)$. These calculations assume the sky is $100 \%$ overcast, and that the cloud does not change during the day.
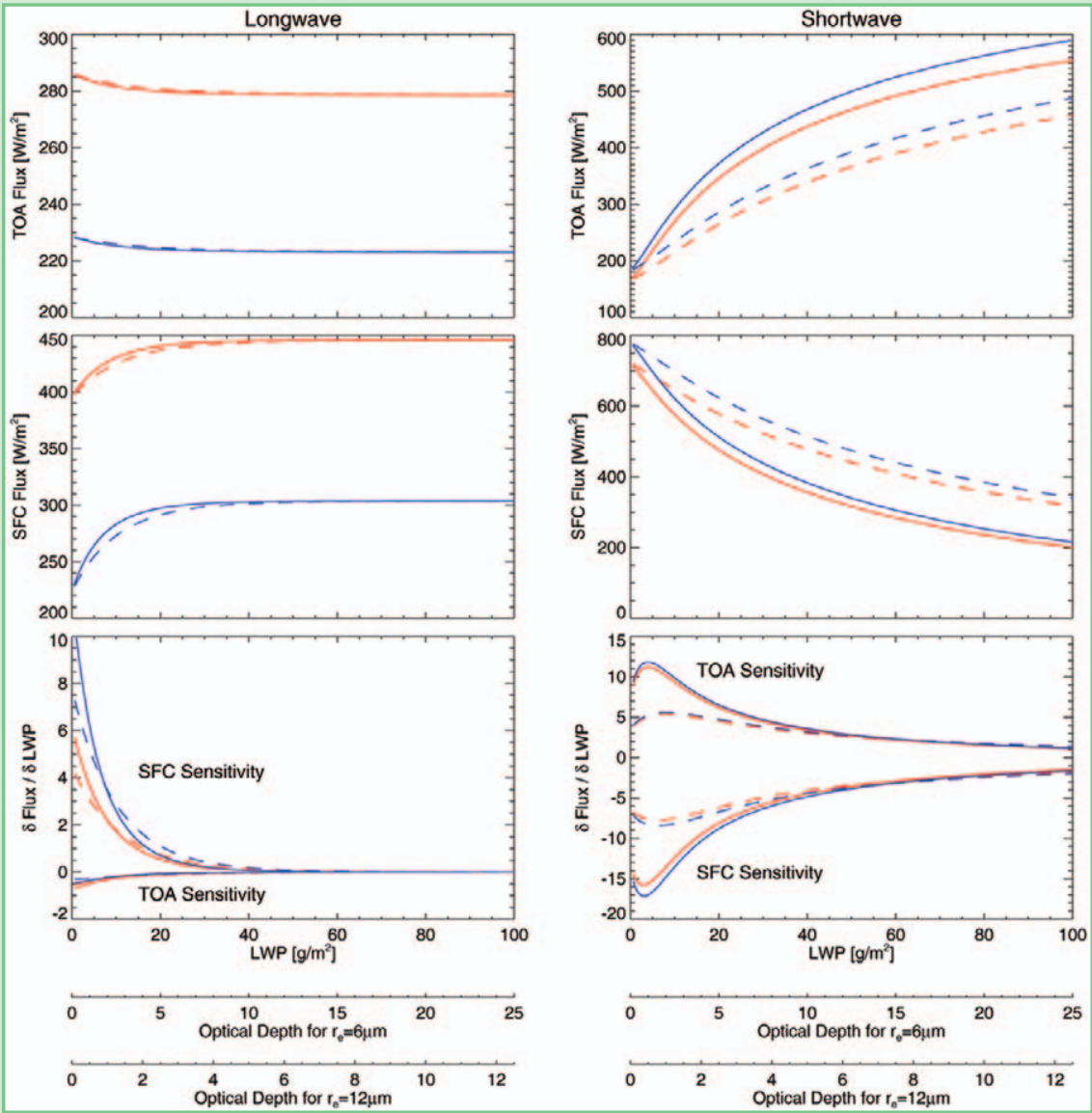
2003). While a $20-30 \mathrm{~g} \mathrm{~m}^{-2}$ uncertainty in the MWRretrieved LWP is insignificant for the many clouds that have large LWP, it represents an unacceptably large uncertainty for the thin clouds that have a LWP of $100 \mathrm{~g} \mathrm{~m}^{-2}$ or less. The accuracy of the retrieval from the MWR is limited by 1) uncertainties in the radiometric observations, 2) uncertainties in the gas spectroscopy (including both water vapor and oxygen) and liquid water dielectric constants used by the microwave absorption models, and, 3) as for any retrieval technique, the uncertainty associated with inverting the forward model (i.e., the retrieval method itself).

Retrieving small LWPs $\left(<100 \mathrm{~g} \mathrm{~m}^{-2}\right)$ also presents a challenge for other remote sensing techniques that use spectral information at visible and infrared wavelengths. Like MWR techniques, spectral infrared retrieval techniques also interpret energy emitted by the atmosphere and, in principle, can run 24 hours a day (i.e., they do not need sunlight). Such infrared methods typically use spectral information from the $8-12-\mu \mathrm{m}$ window and can obtain simultaneous estimates of LWP and effective radius for clouds with optical depths less than about six. However, the cloud must be single layered, the profiles of atmospheric temperature and water vapor need to be known, and the method loses sensitivity for LWPs greater than approximately $50 \mathrm{~g} \mathrm{~m}^{-2}$. In the nearinfrared and visible regime, methods that rely purely on the transmission of solar radiation are complicated by a pronounced nonlinear relationship between optical thickness and the reflected and transmitted fluxes, where scattering rapidly transitions from being single scattering to primarily diffusive. This transition contains the combined influence of the cloud LWP and effective radius that must be separated. Because the dominant type of scattering changes rapidly, small measurement uncertainties can result in large uncertainties in each property. Active remote sensing by cloud radar (i.e., with wavelengths of 3 or $8 \mathrm{~mm}$ ) or lidar can also provide crucial information on the vertical distribution of the cloud liquid water content (LWC; the mass of liquid water in a volume of air). However, lidars are typically limited to cloud optical depths less than about 3 , above which the return signal is fully attenuated. Radars become progressively less sensitive as the cloud drop sizes and LWC decrease, and drizzle in the cloud can lead to substantial errors in the retrieved LWC, especially for shorter-wavelength radars.

Over the last two decades, there has been a marked increase in the number and quality of algorithms that retrieve cloud properties by taking advantage of the radiative properties of clouds in various spectral bands. Each technique may operate well under certain conditions, but thin clouds present a particular challenge. No single technique seems to be able to achieve the desired accuracy and work at the high sampling rate 24 hours a day needed for cloud and climate studies. While our discussion focuses on surface remote sensing, satellite remote sensing must negotiate similar challenging issues (see top-of-atmosphere sensitivities in the "Cloud radiative sensitivity" sidebar) and, for these thin clouds, additional attention is needed for the precise depictions of the surface albedo (for visible methods) or surface skin temperature (for infrared methods). Of course, any of the methods mentioned require independent validation by techniques that can serve as a reference and, with the challenges cited, such a reference currently does not exist.

\section{ADDRESSING THE CHALLENGE: CLOWD.}

One goal of the ARM program is to use long-term observations from its CRFs to improve the parameterization of clouds and their radiative transfer in GCMs (Ackerman and Stokes 2003). Given the frequent occurrence and importance of these thin, liquid water-bearing clouds, ARM recently created a crosscutting focus group called Clouds with Low Optical (Water) Depth (CLOWD; pronounced "klode"). One objective of this group is to compare and evaluate the different remote sensing techniques to retrieve the microphysical properties of clouds with low LWP.

We organized an intercomparison of microphysical property retrievals from a variety of methods. The immense amount of cloud data acquired at the ARM CRFs by multiple sensors provides a unique dataset that enables cross comparisons of different remote sensing techniques. A set of five case study periods were selected from a cloud intensive observation period (IOP) at the ARM Southern Great Plains (SGP) site (Mace et al. 2006), which encompassed the range

\begin{tabular}{|c|c|c|}
\hline Date & Time (UTC) & Comments \\
\hline 14 Mar 2000 & $2020-2150$ & Single-layer overcast warm stratocumulus \\
\hline 15 Mar 2000 & $1730-2230$ & Single-layer cumulus \\
\hline II Mar 2000 & $1630-2200$ & Single-layer cumulus (very tenuous) \\
\hline 12 Mar 2000 & $1630-2200$ & Single-layer, midlevel, mixed-phase cloud \\
\hline 13 Mar 2000 & $1845-2015$ & Midlevel water cloud below thick cirrus \\
\hline
\end{tabular}


of different conditions that fall under the auspices of CLOWD (Table 1). Because of the IOP, additional attention was provided by the various instrument mentors to ensure that high-quality data were collected.
Results from 18 different retrieval algorithms were submitted for these cases. The participants and their retrieval algorithms are summarized in Table 2. The purposes of this exercise were to 1) gain insight into

\begin{tabular}{|c|c|c|c|}
\hline Type & Key name & Contributor & Comments and reference \\
\hline \multirow{4}{*}{ 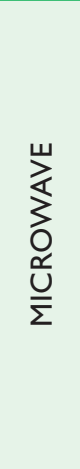 } & ARM Stat & $N / a$ & $\begin{array}{l}\text { MWR LWP, standard ARM product, uses monthly retrieval coefficients } \\
\text { determined from Liebe and Layton (1987) (dry air and water vapor) and Grant } \\
\text { et al. (1957) (liquid water) absorption model (Liljegren and Lesht 1996) }\end{array}$ \\
\hline & Clough Phys & $\begin{array}{l}\text { Clough, Cady-Pereira, } \\
\text { and Turner }\end{array}$ & $\begin{array}{l}\text { MWR LWP, physical iterative method using optimal estimation, absorption } \\
\text { model is monoRTM (Marchand et al. 2003; Turner et al. 2004) }\end{array}$ \\
\hline & Lilj Stat2 & Liljegren and Turner & $\begin{array}{l}\text { MWR LWP, "variable coefficient" method where retrieval coefficients are } \\
\text { predicted from surface meteorological observations; absorption model is } \\
\text { Rosenkranz (1998) (Liljegren et al. 200I; Turner et al. 2004) }\end{array}$ \\
\hline & Lin Phys & Lin & $\begin{array}{l}\text { MWR LWP, physical iterative method using the absorption model Liebe and } \\
\text { Layton (1987) for dry air and water vapor and Ray (1972) for liquid water } \\
\text { (Lin et al. 200I) }\end{array}$ \\
\hline \multirow{4}{*}{ 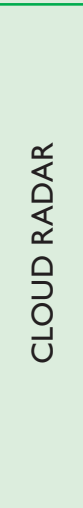 } & MICROBASE & Miller and Johnson & $\begin{array}{l}\text { MMCR LWC and } r_{e} \text { profiles, using the Liao and Sassen (1994) parameterization } \\
\text { of Z-LWC and scaling the LWC profile to match the MWR's LWP (Lilj Stat2) } \\
\text { (Miller et al. 2003) }\end{array}$ \\
\hline & aMMCR & Austin & $\begin{array}{l}\text { MMCR-only retrievals of LWC and } r_{e} \text { profiles for nondrizzling clouds, assum- } \\
\text { ing a column-constant value for the droplet number density [an improved } \\
\text { algorithm derived from Austin and Stephens }(2001) \text { ] }\end{array}$ \\
\hline & aMMCRvod & Austin & $\begin{array}{l}\text { Retrieval of LWC and } r_{e} \text { profiles for nondrizzling clouds, assuming a column- } \\
\text { constant value for the droplet number density, from MMCR reflectivities and } \\
\text { MFRSR-derived visible optical depths [an improved algorithm derived from } \\
\text { Austin and Stephens }(200 \mathrm{I}) \text { ] }\end{array}$ \\
\hline & mMMCR & Matrosov & $\begin{array}{l}\text { MMCR-only retrievals of } L W C \text { and } r_{e} \text { profiles, where drizzle regions are iden- } \\
\text { tified by simple thresholds (Matrosov et al. 2004) }\end{array}$ \\
\hline \multirow{3}{*}{$\frac{\ddot{m}}{\stackrel{m}{\omega}}$} & MFRSR & Min & $\begin{array}{l}\text { MFRSR-derived } \tau \text {, and when MWR LWP (ARM Stat) is included, } r_{e} \text { is also } \\
\text { retrieved and more accurate retrievals of } \tau \text { are realized (Min and Harrison } \\
\text { (1996) }\end{array}$ \\
\hline & NFOV & Marshak and Chiu & $\begin{array}{l}\text { Retrievals of } \tau \text { from the narrow field-of-view zenith radiometer }(870 \mathrm{~nm}) \text { [a } \\
\text { one-channel approach similar to Marshak et al. (2004); Chiu et al. }(2006)]\end{array}$ \\
\hline & Not shown* & Long & $\begin{array}{l}\text { Broadband shortwave retrievals of } \tau \text { using an empirical relationship derived } \\
\text { from Min and Harrison (1996), effective radius is assumed to be } 10 \mu \mathrm{m} \\
\text { (Barnard and Long 2004) }\end{array}$ \\
\hline \multirow{2}{*}{ 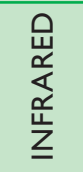 } & MIXCRA v2 & Turner & $\begin{array}{l}\text { AERI-derived } \tau \text { and } r_{\mathrm{e}} \text {, and hence LWP, using radiance observations from } 8 \text { to } \\
13 \mu \mathrm{m} \text { (Turner 2005) }\end{array}$ \\
\hline & MIXCRA v3 & Turner & $\begin{array}{l}\text { AERI-derived } \tau \text { and } r \text {, and hence LWP, using radiance observations from 8-13 } \\
\text { to } 3-5 \mu \mathrm{m} \text { (Turner and Holz 2005) }\end{array}$ \\
\hline \multirow{2}{*}{ 崖 } & VISST & Minnis and Khaiyer & $\begin{array}{l}\text { GOES-8 visible infrared solar split-window technique applied to I0-km- } \\
\text { diameter footprint centered on the SGP site, providing } \tau, r_{\mathrm{e}} \text {, and LWP (Minnis } \\
\text { et al. 1995) }\end{array}$ \\
\hline & Not shown* & Minnis & $\begin{array}{l}\text { Terra Moderate Resolution Imaging Spectroradiometer (MODIS)-retrieved } \\
\text { cloud properties (Minnis et al. 1995) }\end{array}$ \\
\hline \multirow{3}{*}{ 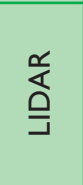 } & Lidar-radar & McFarlane & $\begin{array}{l}\text { Lidar-radar retrievals of } \tau \text { and } r_{e} \text { profiles, for cloud elements seen simultane- } \\
\text { ously by the lidar (MPL) and radar (Donovan and van Lammeren 200I) }\end{array}$ \\
\hline & Not shown* & Wang & Raman lidar retrievals of $\tau$ \\
\hline & Not shown* & Flynn & MPL retrievals of $\tau$ \\
\hline
\end{tabular}

*These datasets were not shown in this manuscript in order to maintain some clarity in Figs. 4, 5, and 6. 
the performance of the different algorithms, 2) identify a means to judge the accuracy of each method, and 3) isolate pressing needs required to improve these retrievals. The ultimate goal of CLOWD is to develop a robust retrieval algorithm that can be automated by the ARM program that draws on the strengths of the best methods to routinely provide accurate LWP and $r$ e at low LWPs for a range of possible sky conditions.

\section{RESULTS: OVERCAST} STRATIFORM CASE.

To simplify the discussion, the remainder of the paper will focus on one of the case study periods. A singlelayer, overcast, stratocumulus cloud existed over the SGP CRF on 14 March 2000 (Figs. 1 and 2). This case is an ideal starting point for the intercomparison, because overcast conditions reduce much of the $3 \mathrm{D}$ influence on the retrieval algorithms and mitigate the possible sampling differences between the methods. Furthermore, a few of the techniques rely on diffuse radiative fields and therefore are only valid on overcast cases. This cloud is also a warm cloud, with temperatures above $5^{\circ} \mathrm{C}$; there is no ice present in the cloud to complicate the analysis. Therefore, this is perhaps the easier case to understand in the initial CLOWD ensemble. ${ }^{3}$ Although this overcast cloud lacks a broken 3D structure immediately above the SGP site, it should be noted that significant internal spatial inhomogeniety (e.g., see Fig. 2) and horizontal inhomogeniety (Fig. 3) exists. One measure of the horizontal inhomogenity of this cloud field is the distri-
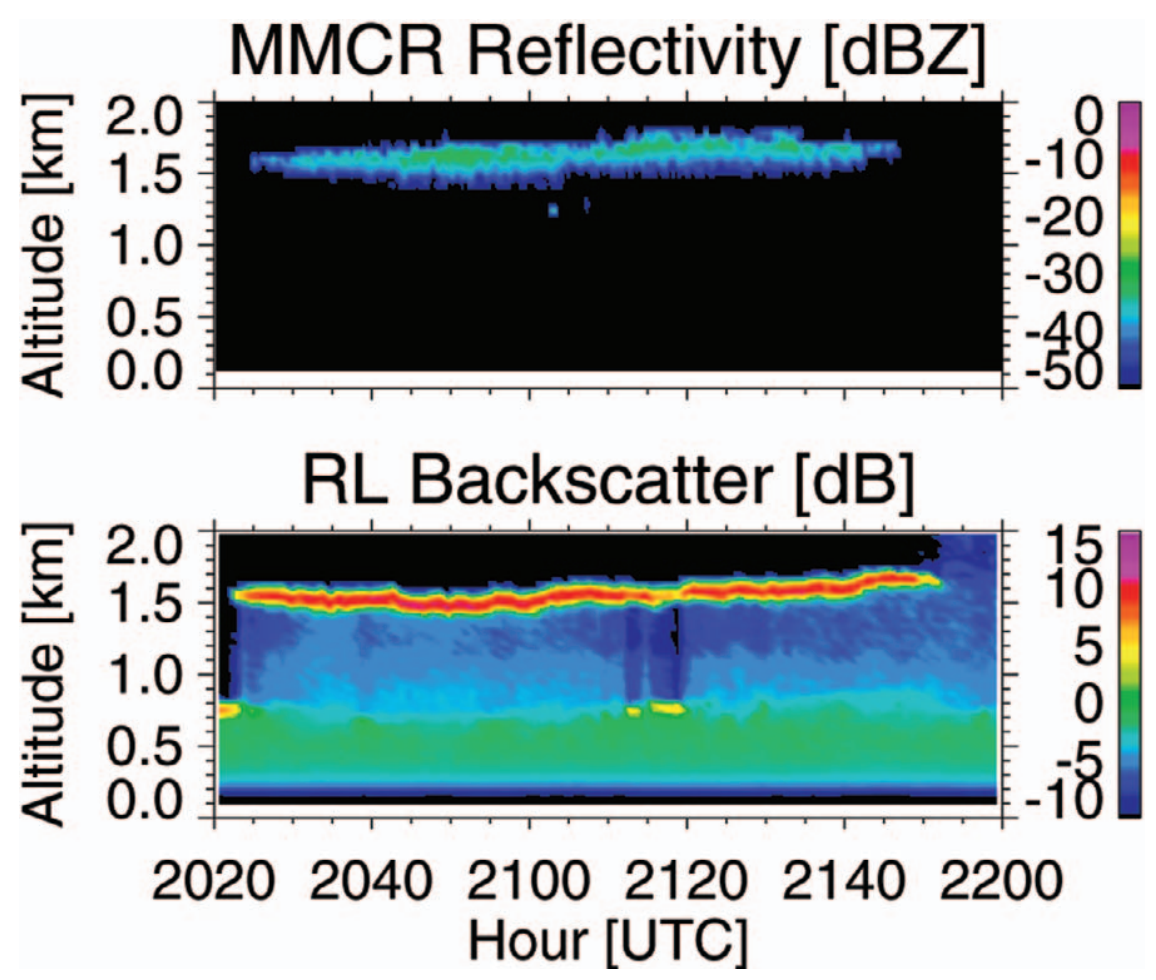

FIG. I. Time-height cross sections of radar reflectivity from the MMCR and elastic backscatter from the Raman lidar $(R L)$ for the warm stratocumulus cloud case on 14 Mar 2000. A very weak low-level cloud return seen in the lidar data at $700 \mathrm{~m}$ between 2115 and 2120 UTC.

bution of the LWP around the SGP site; the LWP retrieved from the nine 4-km Geostationary Operational Environmental Satellite (GOES) pixels closest to the CRF ranges from 6 to $48 \mathrm{~g} \mathrm{~m}^{-2}$ at 2045 UTC. However, while this structure deviates from that for

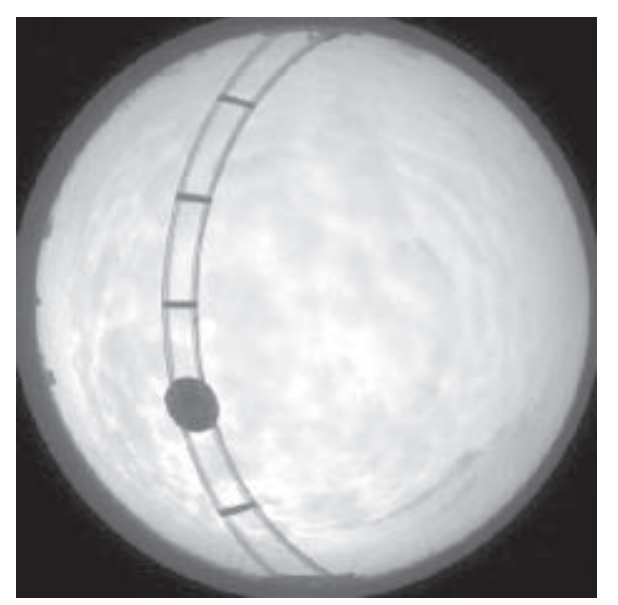

FIG. 2. A sky image collected by the whole-sky imager at 2050 UTC I4 Mar 2000. The sky is completely overcast; however, there is small-scale structure in the cloud field. Note that the solar disk is not discernable in this image. a theoretical horizontally

\footnotetext{
${ }^{3}$ At this point, we would like to remind the reader that we are showing the results from a single case study, and therefore we should refrain from making judgements as to "which algorithm is better." To quantitatively evaluate the different methods, a large number of cases should be analyzed. However, we believe that this single example, because it was selected randomly and the results were submitted by the different participants in a "blind" intercomparison activity, is representative of the differences that currently exists among the techniques that are being used to retrieve LWP, $r_{e}$, and optical depth $(\tau)$ today.
} 


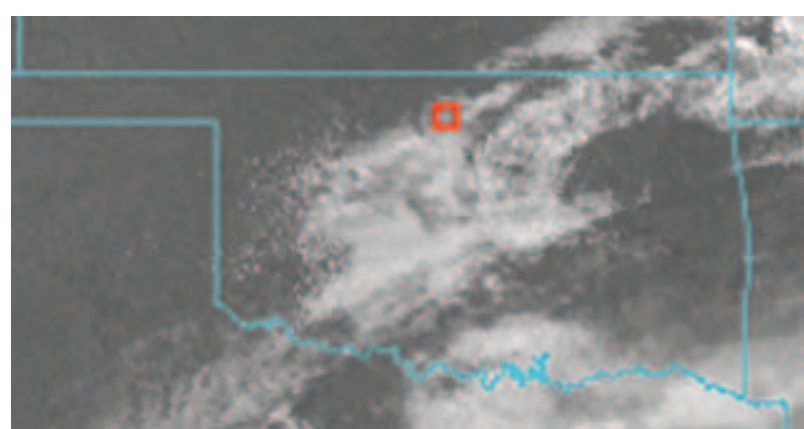

FIG. 3. The $0.65-\mu \mathrm{m}$ reflectance image from GOES -8 at 2045 UTC I4 Mar 2000. The red square denotes the location of the SGP site.

homogenous cloud, it is not unrepresentative for thin clouds.

One MWR dataset: Multiple results. As indicated above, the main tool currently used by ARM to determine the LWP is the MWR. However, the retrieved LWP is sensitive to which absorption model is used in the retrieval (e.g., Westwater et al. 2001; Marchand et al. 2003), as well as to the retrieval method itself. This situation is clearly depicted in Fig. 4, where LWP was retrieved from the same observed MWR brightness temperatures using four different absorption models and three different techniques. The spread between the different LWP values is as large as $40 \mathrm{~g} \mathrm{~m}^{-2}$, which represents a substantial uncertainty relative to the $0-100 \mathrm{~g} \mathrm{~m}^{-2}$ range of LWP values retrieved. This example suggests that the differences between the various algorithms are mainly biases, rather than sensitivity differences (although different sensitivities have been noted between different absorption models (e.g., Westwater et al. 2001).

One cloud radar dataset: Multiple results. Millimeterwave cloud radar (MMCR; Moran et al. 1998) is another critical tool used to retrieve cloud properties at the ARM CRFs. The cloud radar reflectivity $(Z)$ observed by the MMCR is proportional to the sixth moment of the size distribution, that is, $Z \sim \int r^{6} n(r) d r$. There are multiple ways to invert the radar observations and, for our relatively simple case, the four cloud radar-based methods yield significantly different results for LWP, effective radius, ${ }^{4}$ and optical depth (Fig. 5). ${ }^{5}$ Two of these methods only use the radar reflectivity in the retrieval process along with some

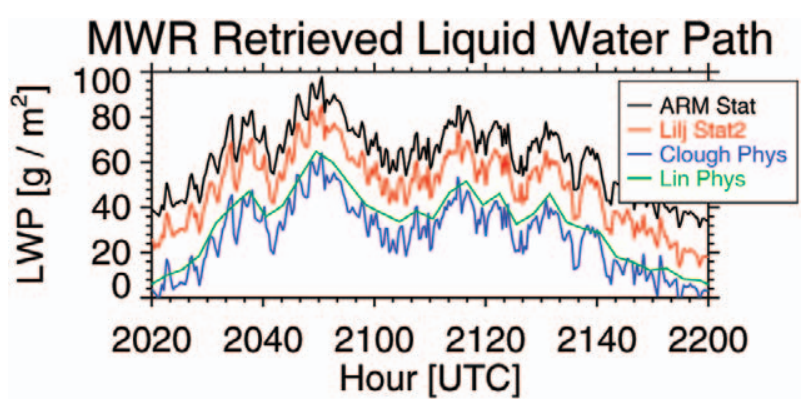

FIG. 4. LWP retrieved from the MWR at the SGP site for the stratiform cloud on 14 Mar 2000 using four different retrieval algorithms (microwave absorption models and inversion techniques). The instantaneous spread in the retrieved LWPs, all which are derived from the same brightness temperature observations, exceeds $40 \mathrm{~g} \mathrm{~m}^{-2}$. The mean values retrieved by the ARM Stat, Lilj Stat2, Clough Phys, and Lin Phys methods for this time period are $62.6,49.5,27.8$, and $33.9 \mathrm{~g} \mathrm{~m}^{-2}$, respectively.

assumptions; however, such assumptions can significantly affect the results (see differences between the aMMCR and mMMCR algorithms). Other radar methods utilize additional observations to help constrain the retrieval, which yield results that are different from the radar-only cases. One technique uses visible optical depth data from the MFRSR (aMMCRvod) and the other uses the LWP from the MWR (MICROBASE) algorithms. [Naturally, if a different MWR LWP retrieval were used (Fig. 4), the MICROBASE results would be affected.] Because optical depth $r_{e}$ and LWP are intimately related (see "Cloud microphysics and remote sensing" sidebar), differences in the retrieved LWP used by the algorithms cause differences in optical depth, and vice versa (provided that both algorithms retrieve similar $r_{e}$ values).

Other techniques. The retrievals from many of the other algorithms are given in Fig. 6, which show substantial differences among the retrieved cloud properties. Differences among the retrieved LWP approach $60 \mathrm{~g} \mathrm{~m}^{-2}$ (Fig. 6a). The LWP used by the MFRSR are from the ARM Stat MWR product, which have the largest values of the MWR retrievals (Fig. 4). Significantly lower LWP are retrieved by the two techniques that utilize infrared observations (MIXCRA v2 and v3) and reflected visible radiation

\footnotetext{
${ }^{4}$ Effective radius $\left(r_{e}\right)$ is a point parameter, and profiles of $r_{e}$ are retrieved by each of the cloud radar methods. However, we are comparing the mean $r_{e}$ averaged over the depth of the cloud.

${ }^{5}$ This case avoids potential complications by large particles because the cloud is warm, and thus free of ice particles, and the low reflectivity observed by the MMCR suggests that this cloud was not drizzling and was free of insect contamination.
} 
(VISST) algorithms. They are in fair agreement (not shown) with the Clough Phys MWR product (Fig. 4), as well as with the radar-only retrievals (mMMCR and aMMCR in Fig. 5a).

Figure $6 \mathrm{~b}$ shows the retrieved values of effective radius, which results in two groupings. A lower range of effective radii, ranging from 3 to $6 \mu \mathrm{m}$, are found by the lidar-radar method (which only provides observations up to the limit of lidar signal attenuation and thus is limited to the bottom of this cloud), MIXCRA v3 (which retrieves cloud properties using radiance observations in both the 8-13- and 3-5- $\mu \mathrm{m}$ band), and MICROBASE (whose values are slightly higher, see Fig. 5a). However, significantly larger effective radii are retrieved by the MFRSR, VISST, and MIXCRA v2 (which use only observations in the $8-13-\mu \mathrm{m}$ band).

The retrieved optical depth data are shown in Fig. 6c. Two algorithms have results that are in fair agreement with each other, but are significantly smaller than the others (VISST and MIXCRA v2). There is fair agreement between several other algorithms at larger values [MFRSR, NFOV, and MICROBASE (not shown)]. The MIXCRA v3 results are between these two sets of results.

All retrieval methods inherently have uncertainty associated with them, and some of the methods above provide rigorous uncertainty estimates (e.g., MIXCRA, aMMCR, and the Clough Phys methods). Given these uncertainties (not shown), the spread in the LWP is still statistically significant. However, even if the uncertainties were large enough that the results were statistically equivalent, this would imply that we, as a cloud property retrieval community, still have a problem resulting from the sensitivity of the radiative flux calculations to uncertainties in LWP when the LWP is small ("Cloud radiative sensitivity" sidebar).

Fig. 5. (a) Retrieved LWP, (b) effective radius, and (c) cloud optical depth from the various algorithms that utilize cloud radar data on I4 Mar 2000. The retrieved cloud properties from each algorithm were used to compute (d) downwelling broadband diffuse flux and (e) radar reflectivity, which were then compared with the observed flux and mean observed radar reflectivity (over the depth of the cloud). The "closure" exercises (gray region) provide sensitivity to LWP (with shortwave diffuse flux) and particle size (with radar reflectivity) primarily. A shaded precision spectral pyranometer (PSP) provides the broadband shortwave diffuse flux observations. The spikes in the aMMCRvod product are caused by the presence of the very thin cloud at $700 \mathrm{~m}$ (Fig. I); these spikes were filtered out of the other radar datasets.
So which is "better"? Given the large spread in the results, we are left with the question, "Which retrieval method yields better results for this cloud?" To this end, we constructed two "closure" experiments. In each experiment, we use the retrieved LWP and column-averaged $r_{e}$ in a model to predict another
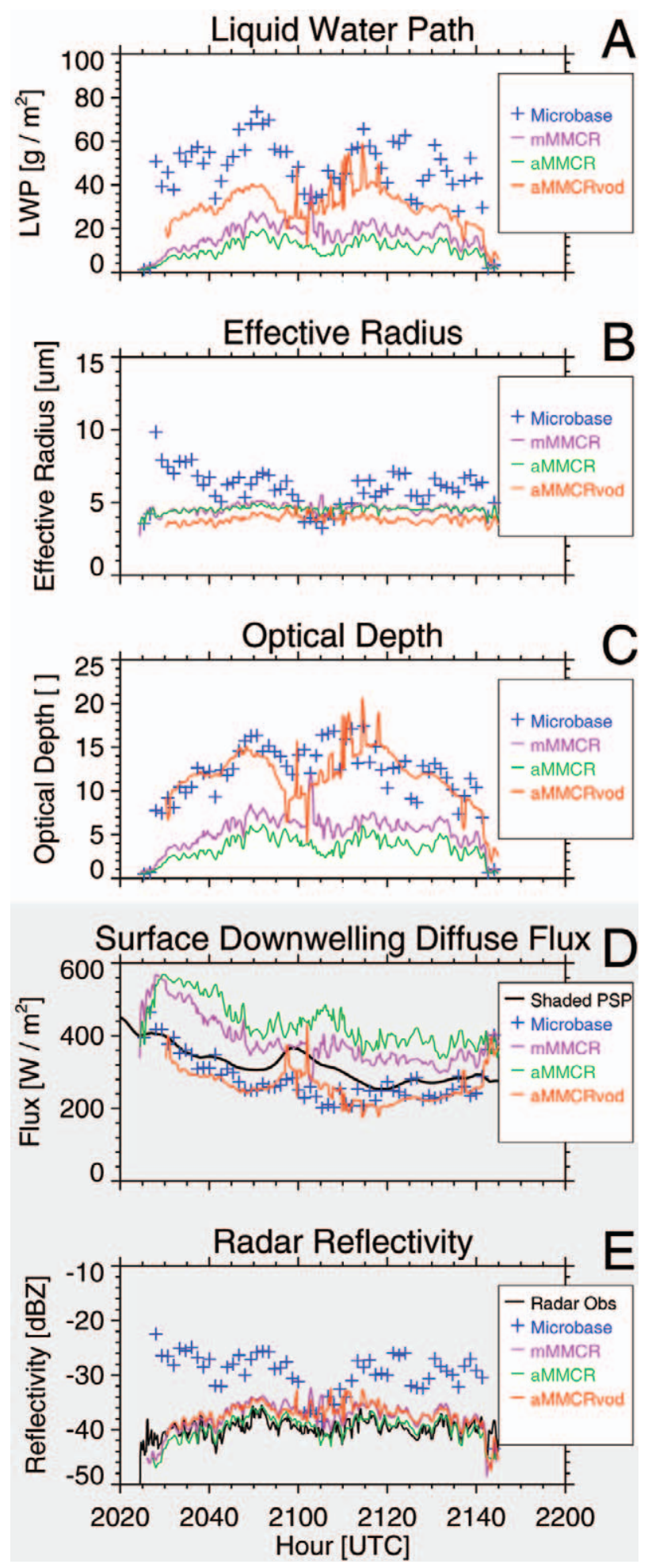

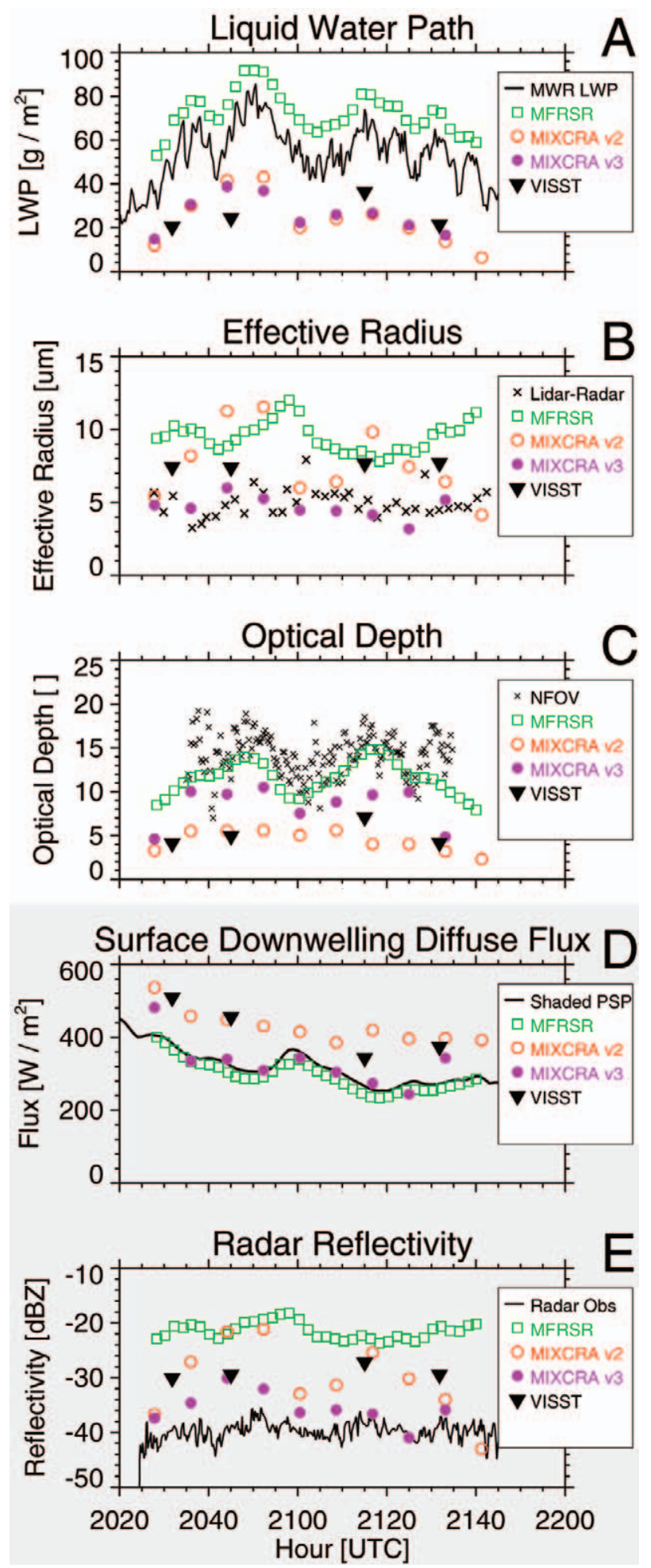

FIG. 6. Similar to Fig. 5 for the retrievals that do not use MMCR data. (a) The MWR LWP data shown are the Lilj Stat2 results. Because the Lilj Stat2 and NFOV methods only provide one of the three variables, and the lidar is fully attenuated by the cloud preventing LWP from being derived by the lidar-radar method, they were not included in the closure exercises. variable, which is compared against other ARM observations. The closure experiments used here compare the observed and calculated broadband downwelling shortwave diffuse flux, and mean radar reflectivity at $35 \mathrm{GHz}$ (in Figs. 5d,e and 6d,e). Both of these variables are sensitive to particle size and LWP; however, the radar reflectivity is more sensitive to the particle size than the LWP, while the opposite is true for the diffuse flux. Therefore, these two closure experiments complement each other and provide two bounds at which to evaluate the adequacy of the different retrievals. ${ }^{6}$

Many conclusions can be drawn from these closure examples. First, the two algorithms that retrieved relatively low optical depths and large particle sizes (VISST and MIXCRA v2) do not close well in either diffuse flux or radar reflectivity (although for different reasons). The MFRSR method closes well in diffuse broadband flux (which is expected because it retrieves the cloud properties from the diffuse flux at $415 \mathrm{~nm}$ ), but does not close well in radar reflectivity. This result suggests that the retrieved particle size is too large. However, if the MFRSR algorithm used LWPs that were smaller (e.g., the Cloud Phys MWR retrieval), then the MFRSR-retrieved results would have closed in both diffuse flux and radar reflectivity (not shown). This highlights the importance of having accurate LWP data to input into the MFRSR algorithm.

The MIXCRA v3 results have a similar level of good agreement in diffuse flux as the MFRSR, and shows better closure (albeit not perfect) in radar reflectivity. The MIXCRA v3 algorithm uses data in the $3-5-\mu \mathrm{m}$ band, while the v2 algorithm does not; this extends the maximum optical depth that can be retrieved by $\mathrm{v} 3$ to approximately $15-20$, while v 2 is limited to approximately 6 . Both algorithms have similar sensitivity to the LWP (Fig. 6a), but, when the true optical depth is above 6 , the inability of the v2 algorithm to retrieve optical depths above this threshold results in a positive bias in the retrieved particle size and negative bias in optical depth.

The primary differences between the two radaronly methods (aMMCR and mMMCR) are associated with their assumptions of the cloud drop number density. Both methods yield similar levels of closure in radar reflectivity but do not close well in diffuse

\footnotetext{
${ }^{6}$ Note that the diffuse flux closure test is applicable because the scene is overcast; in a broken-sky scene the uncertainty associated with the cloud fraction would lead to large uncertainties in the computed fluxes.
} 
flux, with both methods yielding larger fluxes than the observations (implying too little LWP). When the diffuse flux at $415 \mathrm{~nm}$ is included as a constraint, aMMCRvod closes relatively well in shortwave flux (Fig. 5d), but does not close as well in mean radar reflectivity compared to its radar-only counterpart (aMMCR).

Retrievals from another radar-based algorithm, MICROBASE, slightly underestimates the observed diffuse flux while, relative to the other methods, overestimates the particle size. MICROBASE uses the radar reflectivity only in a relative sense to vertically partition the LWP from the MWR, based on the normalized distributions of reflectivity with height. The effective radius is derived from a parameterization based upon the LWC profile. This approach was chosen to optimize the retrieval stability and accuracy over the wide range of cloud conditions found at the SGP. The uncertainties in the MWR LWP and the parameterization are why MICROBASE does not close in radar reflectivity.

To properly judge which retrieval method yields better results, it is also necessary to obtain closure at the top of the atmosphere (TOA), because the difference between the radiation at the top and the bottom determines how much solar radiation is absorbed in the atmosphere. The broadband TOA shortwave fluxes determined from measurements by the Clouds and the Earth's Radiant Energy System (CERES; Wielicki et al. 1996) would be the counterpart to the surface diffuse flux data at the ARM site. While we do not show TOA results here, there are significant differences in TOA shortwave flux among the various retrieved products. Reconciling the discrepancies between the various retrieval techniques will require careful comparisons with a variety of closure "yardsticks" at the surface, within the atmosphere, and from space.

\section{CONCLUSIONS AND OPPORTUNITIES FOR FUTURE RESEARCH. The large differences} found among these state-of-the-art cloud retrievals for this simple case should serve as a rallying cry to the retrieval community to examine the accuracy of their retrieval algorithms for low LWP clouds. While thinner clouds might present complications not shared by their thicker brethren, the pervasiveness of these clouds demands that these differences be resolved for a wide variety of cloud-climate disciplines.

Where do we go from here? Because this is a single case study, more statistical intercomparisons are needed to understand the extent to which these results may be generalized. After we better understand the results for this simple case, we will examine the other case studies that have more challenging scenes, such as broken or mixed-phase clouds. These conditions will challenge not only the retrieval algorithms, but also the construction of the closure study used to evaluate the results. For example, closure in shortwave diffuse flux may not be a viable approach for evaluating the retrievals for a cumulus scene, because the uncertainty in cloud fraction will dominate the uncertainty in the shortwave cloud fluxes.

From the simple stratiform case presented here, we suggest a few prudent avenues of study. More attention is needed to resolve the significant differences that exist among the microwave absorption models, which stem from differences in the spectroscopy and cloud water dielectric constants used, as well as the inversion approach used to retrieve LWP from the microwave radiometer. Also, new methods and instrumentation are needed, which are already being developed. MWRs are being developed with different channels that enhance their sensitivity to small liquid water amounts. For example, including a $90-\mathrm{GHz}$ channel with the standard two-channel system reduces the MWR retrieval uncertainty from 25-30 to approximately $15 \mathrm{~g} \mathrm{~m}^{-2}$ (e.g., Crewell and Löhnert 2003). However, this frequency presents its own challenges regarding instrument calibration and uncertainties in the gas absorption model. Also, new techniques have been developed that determine cloud properties from lidar returns away (off beam) from where the laser beam enters the cloud (Cahalan et al. 2005; Polonsky et al. 2005). While the standard backscattering lidars are limited to clouds with optical depths less than 3, this off-beam approach does not share this limitation. As the knowledge of using active sensors matures, new research avenues arise that use them in combination. For example, Feingold et al. (2003) provide an example of how a combination of cloud radar, lidar, and other ground-based remote sensors may be used to measure the long-term effect of aerosol impact on clouds. Finally, we need to develop better methods to derive the horizontal distribution of the cloud properties with equivalent accuracy, because the distribution of cloud mass is of primary importance in climate models.

We will need to pay close attention to what we consider "truth" for these retrievals. Usually, in situ measurements from airplanes provide an agreed upon truth. However, in the case of thin clouds, significant horizontal and vertical variability exists that complicates obtaining a representative sample. New aircraft 
instrumentation is being developed that would help mitigate this sampling issue by directly observing the cloud optical properties. Examples of such instruments include an airborne transmissometer (Korolev et al. 1999), a cloud extinctometer (Zmarzly and Lawson 2000), a cloud-integrating nephelometer (Gerber et al. 2000), and an in situ lidar (Evans et al. 2003, 2006). Another possibility is the expanded use of unmanned aerial vehicles (UAVs) that resemble large-powered gliders. Because UAVs fly significantly slower than airplanes, cloud probes carried by UAVs would be better suited to adequately sample the cloud variability.

In the end, we need to identify a technique or set of techniques that can routinely observe the microphysical properties and their variability in space and time for all low LWP clouds. It is distinctly possible that the answer might not lie in a single algorithm or instrument, but perhaps in a conjoined algorithm that must be developed. In so doing, we may need to ask the following: is it best to obtain a consensus solution based on a statistical combination of multiple retrieval techniques (e.g., Feingold et al. 2006), or is it best to formulate a single retrieval method that explicitly includes input from many instruments at different wavelengths? It is not clear right now which approach would be best; however, what should be clear is that a lot of interesting and vital research remains to be done.

ACKNOWLEDGMENTS. This research was supported by the Office of Biological and Environmental Research of the U.S. Department of Energy as part of the Atmospheric Radiation Measurement Program.

\section{REFERENCES}

Ackerman, T. P., and G. E. Stokes, 2003: The Atmospheric Radiation Measurement Program. Phys. Today, 56, 38-45.

Austin, R. T., and G. L. Stephens, 2001: Retrieval of stratus cloud microphysical parameters using millimeter-wave radar and visible optical depth in preparation for CloudSat. 1: Algorithm formulation. J. Geophys. Res., 106, 28 233-28 242.

Barnard, J. C., and C. N. Long, 2004: A simple empirical equation to calculate cloud optical thickness using shortwave broadband measurements. J. Appl. Meteor., 43, 1057-1066.

Bender, F. A.-M., H. Rodhe, R. J. Charlson, A. M. L. Ekman, and N. Loeb, 2006: 22 views of the global albedo-Comparison between 20 GCMs and two satellites. Tellus, 58A, 320-330.
Bohren, C. F., and E. E. Clothiaux, 2006: Fundamentals of Atmospheric Radiation. Wiley-VCH, 472 pp.

—, J. R. Linskens, and M. E. Churma, 1995: At what optical thickness does a cloud completely obscure the sun? J. Atmos. Sci., 52, 1257-1259.

Bony, S., and J.-L. Dufresne, 2005: Marine boundary layer clouds at the heart of tropical cloud feedback uncertainties in climate models. Geophys. Res. Lett., 32, L20806, doi:10.1029/2005GL023851.

Cahalan, R. F., M. McGill, J. Kolasinski, T. Varnai, and K. Yetzer, 2005: THOR-Cloud thickness from offbeam lidar returns. J. Atmos. Oceanic Technol., 22, 605-627.

Chiu, J. C., A. Marshak, Y. Knyazikhin, W. Wiscombe, H. Barker, J. C. Barnard, and Y. Luo, 2006: Remote sensing of cloud properties using ground-based measurements of zenith radiance. J. Geophys. Res., 111, D16201, doi:10.1029/2005JD006843.

Crewell, S., and U. Löhnert, 2003: Accuracy of cloud liquid water path from ground-based microwave radiometer-2. Sensor accuracy and synergy. Radio Sci., 38, 8042, doi:10.1029/2002RS002634.

Davis, A. B., A. Marshak, H. Gerber, and W. J. Wiscombe, 1999: Horizontal structure of marine boundary layer clouds from centimeter to kilometer scales. $J$. Geophys. Res., 104 (D6), 6 123-6 144.

Donovan, D. P., and A. C. A. P. van Lammeren, 2001: Cloud effective particle size and water content profile retrievals using combined lidar and radar observations. Part 1. Theory and examples. J. Geophys. Res., 106, 27 425-27 448.

Evans, K. F., R. P. Lawson, P. Zmarzly, D. O'Connor, and W. J. Wiscombe, 2003: In situ cloud sensing with multiple scattering lidar: Simulations and demonstration. J. Atmos. Oceanic Technol., 20, 1505-1522.

—, D. O'Connor, P. Zmarzly, and R. P. Lawson, 2006: In situ cloud sensing with multiple scattering lidar: Design and validation of an airborne sensor. $J$. Atmos. Oceanic Technol., 23, 1068-1081.

Feingold, G., W. L. Eberhard, D. E. Veron, and M. Previdi, 2003: First measurements of the Twomey indirect effect using ground-based remote sensors. Geophys. Res. Lett., 30, 1287, doi:10.1029/2002GL016633.

—, R. Furrer, P. Pilewskie, L. A. Remer, Q. Min, and H. Jonsson, 2006: Aerosol indirect effect studies at the Southern Great Plains during the May 2003 Intensive Operations period. J. Geophys. Res,. 111, D05514, doi:10.1029/2005JD005648.

Gerber, H., Y. Takano, T. J. Garrett, and P. V. Hobbs, 2000: Nephelometer measurements of the asymmetry parameter, volume extinction coefficient, and backscatter ratio in Arctic clouds. J. Atmos. Sci., 57, 3021-3034. 
Grant, E. H., J. Buchanan, and H. F. Cook, 1957: Dielectric behavior of water at microwave frequencies. $J$. Chem. Phys., 26, 156-161

Hartmann, D. L., M. E. Ockert-Bell, and M. L. Michelsen, 1992: The effect of cloud type on the earth's energy balance: Global analysis. J. Climate, 5, 1281-1304.

Houghton, 2001: Climate Change 2001: The Scientific Basis. Cambridge University Press, 881 pp.

Korolev, A. V., G. A. Isaac, J. W. Strapp, and A. N. Nevzorov, 1999: In situ measurements of effective diameter and effective droplet number concentration. J. Geophys. Res., 104, 3993-4003.

Liao, L., and K. Sassen, 1994: Investigation of relationships between Ka-band radar reflectivity and ice and liquid water contents. Atmos. Res., 34, 231-248

Liebe, H. J., and D. H. Layton, 1987: Millimeter wave properties of the atmosphere: Laboratory studies and propagation modeling. NTIA Rep. 87-24.

Liljegren, J. C., and B. M. Lesht, 1996: Measurements of integrated water vapor and cloud liquid water from microwave radiometer at the DOE ARM cloud and radiation testbed in the Southern Great Plains. Proc. Int. Geoscience Remote Sensing Symp., Lincoln, NB, IGARSS, 1675-1677.

—_, E. E. Clothiaux, G. G. Mace, S. Kato, and X. Dong, 2001: A new retrieval for cloud liquid water path using a ground-based microwave radiometer and measurements of cloud temperature. J. Geophys. Res., 106, 14 485-14 500.

Lin, B., P. Minnis, A. Fan, J. A. Curry, and H. Gerber, 2001: Comparison of cloud liquid water paths derived from in situ and microwave radiometer data taken during the SHEBA/FIREACE. Geophys. Res. Lett., 28, 975-978.

Mace, G. G., S. Benson, and S. Kato, 2006: Cloud radiative forcing at the Atmospheric Radiation Measurement Program Climate Research Facility: 2. Vertical redistribution of radiant energy by clouds. J. Geophys. Res., 111, D11S91, doi:10.29/2005JD005922.

Marchand, R., T. Ackerman, E. R. Westwater, S. A. Clough, K. Cady-Pereira, and J. C. Liljegren, 2003: An assessment of microwave absorption models and retrievals of cloud liquid water using clearsky data. J. Geophys. Res., 108, 4773, doi:10.1029/ 2003JD003843.

Marshak, A., Y. Knyazikhin, K. D. Evans, and W. J. Wiscombe, 2004: The "RED versus NIR" plane to retrieve broken-cloud optical depth from groundbased measurements. J. Atmos. Sci., 61, 1911-1925.

Matrosov, S. Y., T. Uttal, and D. A. Hazen, 2004: Evaluation of radar reflectivity-based estimates of water content in stratiform marine clouds. J. Appl. Meteor., 43, 405-419.
McClatchey, R. A., and Coauthors, 1972: Optical properties of the atmosphere. Air Force Cambridge Research Laboratory Environmental Research Paper AFORL-72-0497, 108 pp.

McFarlane, S. A., and K. F. Evans, 2004: Clouds and shortwave fluxes at Nauru. Part I: Retrieved cloud properties. J. Atmos. Sci., 61, 733-744.

Mie, G., 1908: Beitrage zur Optik trüber Medien speziell kolloidaler Metallösungen. Ann. Phys., 25, 377-445.

Miller, M. A., K. L. Johnson, D. T. Troyan, E. E. Clothiaux, E. J. Mlawer, and G. G. Mace, 2003: ARM value-added cloud products: Description and status. Proc. of the 13th ARM Science Team Meeting, Broomfield, CO, ARM. [Available online at www. arm.gov/publications/proceedings/confl3/extended_abs/miller-ma.pdf.]

Min, Q., and L. C. Harrison, 1996: Cloud properties derived from surface MFRSR measurements and comparison with GOES results at the ARM GSP site. Geophys. Res. Lett., 23, 1641-1644.

Minnis, P., and Coauthors, 1995: Clouds and the Earth's Radiant Energy System (CERES) Algorithm Theoretical Basis Document, Volume III: Cloud analyses and radiance inversions (Subsystem 4). NASA RP 1376, 176 pp.

Moran, K. P., B. E. Martner, M. J. Post, R. A. Kropfli, D. C. Welsh, and K. B. Widener, 1998: An unattended cloud-profiling radar for use in climate research. Bull. Amer. Meteor. Soc., 79, 443-455.

Polonsky, I. N., S. P. Love, and A. B. Davis, 2005: Wide-angle imaging lidar deployment at the ARM Southern Great Plains site: Intercomparison of cloud property retrievals. J. Atmos. Oceanic Technol., 22, 628-648.

Ray, P., 1972: Broadband complex refractive indices of ice and water. Appl. Opt., 11, 1836-1844.

Rosenkranz, P. W., 1998: Water vapor continuum absorption: A comparison of measurements and models. Radio Sci., 33, 919-928.

Rossow, W. B., and R. A. Schiffer, 1999: Advances in understanding clouds from ISCCP. Bull. Amer. Meteor. Soc., 80, 2261-2287.

Schmetz, J., 1984: On the parameterization of the radiative properties of broken clouds. Tellus, 36A, 417-432.

Sengupta, M., E. E. Clothiaux, T. P. Ackerman, S. Kato, and Q. Min, 2003: Importance of accurate liquid water path for estimation of solar radiation in warm boundary layer clouds: An observational study. J. Climate, 16, 2997-3009.

Shupe, M. D., and J. M. Intrieri, 2004: Cloud radiative forcing of the Arctic surface: The influence of cloud 
properties, surface albedo, and solar zenith angle. $J$. Climate, 17, 616-628.

Slingo, A., S. Nicholls, and J. Schmetz, 1982: Aircraft observations of marine stratocumulus during JASIN. Quart. J. Roy. Meteor. Soc., 108, 833-856.

Stephens, G. L., 1994: Remote Sensing of the Lower Atmosphere. Oxford University Press, 523 pp.

— , and Coauthors, 2002: The CLOUDSAT mission and the A-Train. Bull. Amer. Meteor. Soc., 83, 1771-1790.

Turner, D. D., 2005: Arctic mixed-phase cloud properties from AERI-lidar observations: Algorithm and results from SHEBA. J. Appl. Meteor., 44, 427-444.

— , and R. E. Holz, 2005: Retrieving cloud fraction in the field-of-view of a high-spectral-resolution infrared radiometer. Geosci. Remote Sens. Lett., 3, 287-291.

— , K. L. Gaustad, S. A. Clough, K. Cady-Pereira, M. J. Mlawer, J. C. Liljegren, and E. E. Clothiaux, 2004: Improved PWV and LWP retrievals from the microwave radiometer for ARM. Proc. of the 14th ARM Science Team, Albuquerque, NM, ARM. [Available online at www.arm.gov/publications/proceedings/ confl4/extended_abs/turner3-dd.pdf.]
Twomey, S., 1974: Pollution and the planetary albedo. Atmos. Environ., 8, 1251-1256.

Westwater, E. R., Y. Han, M. D. Shupe, and S. Matrosov, 2001: Analysis of integrated cloud liquid and precipitable water vapor retrievals from microwave radiometers during the Surface Heat Budget of the Arctic Ocean project. J. Geophys. Res., 106, 32 019-32 030.

Wielicki, B. A., B. R. Barkstrom, E. F. Harrison, R. B. Lee III, G. L. Smith, and J. E. Cooper, 1996: Clouds and the Earth's Radiant Energy System (CERES): An Earth Observing System experiment. Bull. Amer. Meteor. Soc., 77, 853-868.

Zhang, M. H., and Coauthors, 2005: Comparing clouds and their seasonal variations in 10 atmospheric general circulation models with satellite measurements. J. Geophys. Res., 110, D15S02, doi:10.1029/ 2004JD005021.

Zmarzly, P. M., R. P. Lawson, 2000: An optical extinctometer for cloud radiation measurements and planetary exploration. Final report submitted to NASA Goddard Space Flight Center in fulfillment of Contract NAS5-98032, 131 pp.

Zuidema, P., and D. L. Hartmann, 1995: Satellite determination of stratus cloud microphysical properties. J. Climate, 8, 1638-1657. 